
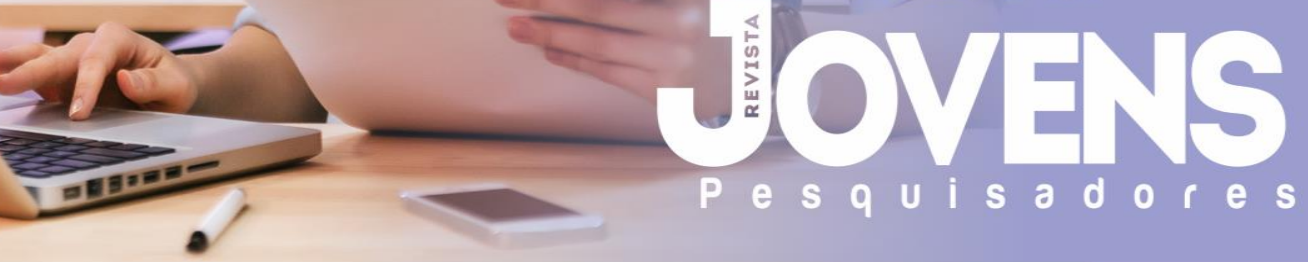

\title{
INCENTIVO AO ESTUDO DA MATEMÁTICA NOS ANOS FINAIS DO ENSINO FUNDAMENTAL
}

\author{
MELLO, F. J.1; KLAMT, S.C. ${ }^{2}$.
}

PALAVRAS-CHAVE: Educação matemática. Metodologias inovadoras. Ensino.

\section{RESUMO}

0 presente trabalho tem como questão norteadora os motivos que fazem os alunos terem pavor da matemática nos anos finais do ensino fundamental. Foram analisados os fatores que podem interferir e causar este certo temor ao ensino da matemática. 0 trabalho partiu da ideia de que os professores podem buscar alternativas diversas para incentivar o gosto pela disciplina nos discentes. 0 uso de metodologias inovadoras, capazes de deixar claro a importância e aplicação da mesma no nosso cotidiano é uma das possibilidades. Por conta da pandemia de COVID-19, o trabalho teve que ser adequado para ser realizado na modalidade remota. Dessa forma, o que era para ser na forma presencial teve que ser adequado para o formato remoto. No entanto, a adequação não impediu o levantamento de aspectos considerados importantes pelo público-alvo para uma aprendizagem mais prazerosa da matemática. Entre os principais resultados, tem-se a mensão do papel do professor como principal agente motivador na aprendizagem, o que está interligado à outro aspecto muito mencionado que é a metodologia. Os entrevistados afirmaram sentirem-se desafiados e aprendem com prazer quando os conteúdos são trabalhados de forma contextualizada ao seu dia-a-dia.

\section{INCENTIVE TO STUDY MATHEMATICS IN THE FINAL YEARS OF ELEMENTARY EDUCATION}

KEYWORDS: Math education. Innovative methodologies. Teaching

\begin{abstract}
The present work has as its guiding question the reasons that make students terrified of mathematics in the final years of elementary school. The factors that can interfere and cause this certain fear in the teaching of mathematics were analyzed. The work started from the idea that teachers can seek different alternatives to encourage the taste for discipline in students. The use of innovative methodologies, capable of clarifying its importance and application in our daily lives, is one of the possibilities. Due to the COVID-19 pandemic, the work had to be adequate to be carried out in the remote mode. In this way, what was supposed to be in the face-to-face form had to be adequate for the remote format. However, the adequacy did not prevent the survey of aspects considered important by the target audience for a more pleasurable learning of mathematics. Among the main results, there is the mention of the teacher's role as the main motivating agent in learning, which is linked to another aspect that is frequently mentioned, which is the methodology. Respondents stated that they feel challenged and learn with pleasure when the contents are worked in a contextualized way to their daily lives.
\end{abstract}




\section{INTRODUÇÃO}

O tema central deste trabalho está relacionado às práticas pedagógicas no ambiente escolar. A relevância do trabalho concentra-se em contribuir com a identificação junto à comunidade escolar, mais especificamente nos anos finais do Ensino Fundamental, de elementos que contribuam para um ensino da matemática mais atrativo, prazeroso, e deixe de ser uma disciplina antagônica em nossas instituições de ensino, dando espaço para que a formação integral do aluno seja atingida. Sendo assim, como objetivo, buscou-se detectar oportunidades no sistema educacional e levantar algumas soluções práticas para incentivar o gosto pela matemática nos anos finais do ensino fundamental. Estavam previstas 20 horas de aplicação presencial para vinte e um alunos do $7^{\circ}$ ano de Ensino Fundamental da Escola Estadual de Esino Fundamental Farrapos localizada no município de Encantado, RS. Por conta da pandemia de COVID-19, o trabalho teve que ser adequado para ser realizado na modalidade remota. Através do Google Meet, as atividades ocorreram de forma síncrona, com significativa adesão dos alunos. Metodologicamente, iniciava-se os encontros com uma mobilização e construção do conteúdo personalizados, através do uso do Power Point e Vídeos. Posteriormente, de modo assíncrono, através do Google Sala de Aula (Classroom), Google Formulário, jogos online trabalhavam na execução de diversas técnicas de assimilação do conteúdo. As atividades foram muito bem aceitas pelos alunos. Percebia-se claramente a admiração dos mesmos a cada atividade diferente, e a clássica frase: "Não sabia que a matemática podia ser tão legal".

Este artigo está organizado nas seguintes seções: seção 1 faz a apresentação do trabalho, a seção 2 apresenta a fundamentação teórica envolvida na pesquisa; a seção 3 apresenta a proposta metodológica para o desenvolvimentos do projeto; a seção 4 reúne os reultados obtidos e a seção 5 as conclusões.

\section{FUNDAMENTAÇÃO TEÓRICA}

Estudar, vem a ser um ato que não é uma prática de todos, e quando nos referimos ao ensino fundamental, esta questão piora quando entramos na "matemática". Equações, subtração, expressões, entre outros conteúdos, acabam se tornando tópicos pavorosos que causam antipatia, tendo consequências nada agradáveis para os alunos. Pesquisadores da Universidade de Chicago, no estado de Illinois, concluíram que o medo causado pelo estudo da matemática pode causar dor de cabeça e outros efeitos colaterais. Foi realizado uma pesquisa com vinte e oito discentes, sendo que metade destes, sentiam medo diante da matemática. Com o auxílio de neurotransmissores, foi aplicado um exame de matemática com os alunos. Como resultado, foi constatado que os alunos que tinham "medo", ativavam na execução do teste, partes do cérebro responsáveis pela sensação de dor, comprovando deste modo a tese de que o temor a matemática (ou a qualquer área), pode sim, causar dor de cabeça (LYONS \& BEILOCK, 2012).

0 medo pela disciplina de matemática pode ir muito além de sintomas como os citados acima, como por exemplo, a discalculia, que vem a ser a incapacidade de lidar com operações triviais. Sobre o diagnóstico desta doença, para ser preciso, é necessário excluir casos de deficiência intelectual, ambientes escolares ou familiares conturbados, problemas com a afetividade entre outros mais complexos. 
Temos que reconhecer que a matemática tem sido considerada, em demasia, como uma matéria detestada pela maioria dos alunos, ou como uma área que só pode ser bem compreendia por uma minoria dos mesmos. Desde que um aluno passe a temer a matemática, começa esse ciclo crescente e vicioso, de ansiedade matemática e de deficiência no seu aprendizado. Não é mais compreensível presenciarmos professores que parecem sentir prazer em dar à matemática uma impressão de algo difícil de ser entendido. (VITTI, 1996, p. 26).

A discalculia é um transtorno que faz com que muitas crianças tenham problemas quanto à compreensão de quantidade e conceitos de maior e menor. Este mesmo público expressa problemas como dificuldades para se recordar de fatos envolvendo a aritmética. Muitas vezes, compreendem a lógica por trás da matemática, mas não como ou quando aplicá-la. A nomenclatura da discalculia, muitas vezes, acaba sendo confundida com a dislexia, que é um transtorno voltado à dificuldade de leitura, sendo assim, "batizada" em diversos casos de dislexia matemática, deficiência de aprendizagem em matemática, dentre outros nomes. Diversos profissionais podem auxiliar pessoas com este diagnóstico. Os mais procurados são os professores de educação especial, neuropsicólogos, psicólogos, psicopedagogos, terapeutas educacionais e tutores de matemática (MORAES,2012).

É muito comum observarmos nos estudantes o desinteresse pela matemática, o medo da avaliação, pode ser contribuído, em alguns casos, por professores e pais para que esse preconceito se acentue. Os professores na maioria dos casos se preocupam muito mais em cumprir um determinado programa de ensino do que em levantar as ideias prévias dos alunos sobre um determinado assunto. Os pais revelam aos filhos a dificuldade que também tinham em aprender matemática, ou até mesmo escolheram uma área para sua formação profissional que não utilizasse matemática. (VITTI, 1999, p. 32/33).

A busca por uma formação profissional para o ensino da matemática traz à tona diversas demandas e possibilidades para um olhar mais didático e humanístico para esta área que é, muitas vezes, só percebida em sua racionalidade. A primeira escolha que desafiou esta reflexão fora o ponto de partida, o qual emergiu com os Parâmetros Curriculares Nacionais-PCNs. A alternativa para olhar a realidade circunscrita e cotidiana é a ludicidade, trazida como um caminho para aproximar os recursos lógico-matemáticos às necessidades dos educandos. Inevitavelmente, o educador é o foco de atenção, pois está nele a responsabilidade de realizar um bom trabalho didático no processo educacional.

Considerar a urgência de ampliar as discussões dessa visão mais humanística do ensino da Matemática é um caminho primordial a percorrer. A boa notícia está em já haver grandes passos dados por pesquisadores que têm se dedicado a criar possibilidades para o ensino que escape ao tradicional. 0 lúdico é um grande aliado da aproximação entre a vida cotidiana e a matemática, oferecendo condições satisfatórias para sua compreensão.

0 ensino através da utilização de recursos lúdicos promove a interação entre alunos e professores, desenvolvendo a inteligência interpessoal e emocional, que resulta no diálogo e na cooperação entre os pares. Sobre isso, é possível recorrer a outro estudo, Mendes e Silva (2011, p.2), no qual apontam que "o educador deve priorizar o ato de encorajar a criança a pensar autonomamente em todos os tipos de situação" para que a criança manifeste o desejo de pensar logicamente.

0 mundo atual é rapidamente mutável, a escola como os educadores devem estar em contínuo estado de alerta para adaptar-se ao ensino, seja em conteúdo como a metodologia, a evolução dessas mudanças que afetam tantas condições materiais de vida como do espírito com que os indivíduos se adaptam a tais mudanças. Em caso contrário, se a escola e os educadores descuidarem e se manterem estáticos ou com movimento vagaroso em comparação com a velocidade externa, origina-se um afastamento entre a escola e a realidade ambiental, que faz com que os alunos se sintam pouco atraídos pelas atividades de aula e busquem adquirir por meio de uma educação informal os 
conhecimentos que consideram necessários para compreender a sua maneira no mundo externo. (PARRA, 1993, p. 11).

Nesta busca do despertar do interesse pelo desenvolvimento do intelecto através dos conhecimentos da matemática, há inúmeros educadores e escolas aplicando atividades lúdicas em diversas áreas do conhecimento. O lúdico, não é uma novidade mas precisamos jogá-lo em cena, para atrair o foco sobre ele. Segundo os estudos de Mendes e Silva (2011), jogos e brincadeiras aplicados nessa disciplina ajudam os alunos a desenvolverem habilidades como imaginação, memorização, noção de espaço e atenção, absorvendo o conhecimento de forma descontraída e dinâmica. Além disso, o lúdico somado ao aprender faz com que os alunos sintam prazer no contato com a Matemática, potencializando a compreensão dos conceitos e suas aplicações.

Dentro da situação de jogo, onde é impossível uma atitude passiva e a motivação é grande, notamos que, ao mesmo tempo em que estes alunos falam matemática, apresentam também um melhor desempenho e atitudes mais positivas frente a seus processos de aprendizagem (BORIN, 1996, p. 9).

Mais um ponto forte que deve levar ao educador matemático a dar atenção às atividades lúdicas na escola é a capacidade que estes recursos têm de proporcionar um relacionamento mais estreito entre professores e alunos, além de favorecer a interação entre os estudantes e proporcionar uma sensação de bem-estar e prazer ao longo do processo de aprendizagem.

O jogo lúdico é formado por um conjunto linguístico que funciona dentro de um contexto social; possui um sistema de regras e se constitui de um objeto simbólico que designa também um fenômeno. Portanto, permite ao educando a identificação de um sistema de regras que permite uma estrutura sequencial que especifica a sua moralidade". (PIAGET, 1984, p. 44).

Ao educador fica a responsabilidade intransferível de realizar um bom trabalho didático, efetivando a aprendizagem, criando e recriando recursos didáticos que contribuam com o processo educacional de cada aluno. Isso nada tem de vocacional, mas de profissionalismo e formação contínua; de observação às diferentes realidades, de seus educandos e contextos, fazendo com que a matemática efetivamente desenvolva as habilidades que cabem a esta área de conhecimento e participe da formação integral dos sujeitos.

\section{MATERIAIS E MÉTODOS}

Para o estudo a amostra constou de uma turma de vinte e um alunos do $7^{\circ}$ ano do Ensino Fundamental da E.E.E.F. Farrapos do município de Encantado, RS. Para avaliar a validade ou não das técnicas utilizadas, foi utilizado um questionário respondido pelos alunos envolvidos, através do Google Formulários (Anexo A).

De forma objetiva procurou-se relacionar diferentes conteúdos da matemática à sua aplicabilidade no dia a dia e, dessa forma, despertar o interesse e a criatividade do aluno, tornando-se uma ferramenta para sua assimilação. Estudos (DULLIUS, 2015; SILVA, 2019; BRANDT e MORETTI, 2016) compravam que a Construção do Aprendizado pode ocorrer de maneiras múltiplas. Sendo assim, foi proposto aos alunos o uso de diferentes técnicas de ensino da matemática, como aula simulada, régua operatória, teatro, construção de paródia, história em quadrinhos, entre outras técnicas, dando a oportunidade ao aluno de construir e expressar o conhecimento de diversas maneiras. Os encontros foram de forma síncrona através do google meet, sendo a primeira parte da 
aula reservada para exposição do conteúdo e orientações sobre a técnica a ser utilizada. Na segunda parte da aula, o aluno desenvolvia de forma assíncrona, atividades de forma individual ou em grupo de acordo com as orientações do professor. Na aula seguinte ocorre a socialização das atividades individualmente ou de cada grupo.

Dessa forma, no uso da técnica da "Aula Simulada" os alunos foram solicitados para em grupos elaborar uma aula simulada e apresentar para os colegas via google meet. Nesse método, o aluno deixa de ser um expectador e passa a atuar ativamente, tornando-se o protagonista e o professor deixa de atuar como palestrante, assumindo uma postura de orientador e tutor. Essa técnica se aplica bem em qualquer assunto a ser desenvolvido. Para abordar a temática de adição e subtração de números inteiros, a técnica utilizada foi a da "Régua Operatória". Construída pelos próprios alunos, é formada por duas retas numéricas que vão do -9 ao 9 e que podem ser movidas para a direita e para a esquerda, permitindo resolver somas e subtrações. Movimentando as escalas, o estudante compreende cada passo da operação e chega mais facilmente ao resultado.Para o estudo sobre divisão de números inteiros a técnica utilizada foi a do "Jogo da Memória".

O jogo da memória é um clássico jogo formado por peças que apresentam uma figura em um dos lados e pode ser jogado em duplas ou gupos maiores. As figuras podem ser substituidas por operações matemáticas do tipo operação e resposta. Como produto foi solicitado a confecção do jogo e elaboração de um vídeo documentando a participação da família nas atividades. A potenciação de números inteiros e sua presença no cotidiano foi estudada através de aula síncrona e assíncrona, onde o professor orienta os alunos e explica o conteúdo. Como fechamento solicita uma atividade em forma de entrevista a qual os alunos apresentam na aula seguinte, oportunidade em que todos os dados são reunidos em um único documento.

Cosiderando que a história em quadrinhos é uma forma criativa de produzir conteúdo matemático com design e visual atrativo, foi a técnica que serviu de suporte para abordar o conteúdo referente a expressões numéricas e sua presença no cotidiano. Todas as atividades puderam ser realizadas individualmente ou em grupo de livre escolha entre os alunos e a apresentação sempre via google meet organizada pelo professor.

\section{RESULTADOS E DISCUSSÃO}

Em nosso meio, é muito comum conhecer-se pessoas afirmando que não gostam de matemática. Esta problemática nos leva a pensar nas razões que fazem com que a mesma se concretize. Neste sentido, foi possível analisar através das atividades desenvolvidas, que o desinteresse pode ser adquirido pela maneira como os conteúdos em pauta são trabalhados com o aluno. Através da pesquisa realizada com 21 alunos de uma turma de $7^{\circ}$ ano do Ensino Fundamental, foi possível notar que grande parte dos mesmos já detestou a matéria, confirmando o que pesquisas afirmam sobre a mesma ser considerada uma disciplina antagônica na vida de muitos discentes. Tendo essa percepção e consciência, uma das primeiras indagações feita aos entrevistados, se concentrou em saber os motivos pelos quais não gostam da disciplina que estuda os números. As respostas foram bem variadas, vindo ao encontro a complexidade da disciplina, o gosto pessoal de cada pessoa e o professor como figura importante neste processo. Neste último ponto levantado pelos alunos, é salientada a falta de associação ao cotidiano, o medo imposto pelos docentes, a falta de diálogo e amizade entre docente e discente, dificultando assim o aprendizado da mesma. A discalculia, que foi um ponto apresentado na fundamentação teórica, também fez parte da entrevista. Logo no início do questionário, os estudantes foram convidados a 
responder se os mesmos teriam conhecimento, que em alguns casos a dificuldade com as disciplinas da área das exatas, poderia estar ligada a este transtorno. Surpreendentemente, mais de $80 \%$ dos adolescentes responderam que já conheciam o transtorno de discalculia. A Figura 1 ilustra os apontamentos dos alunos sobre a temática.

Figura 1: Gráfico analisando as atividades de maior eficácia segundo resposta dos alunos no auxilio ao ensino da matemática.

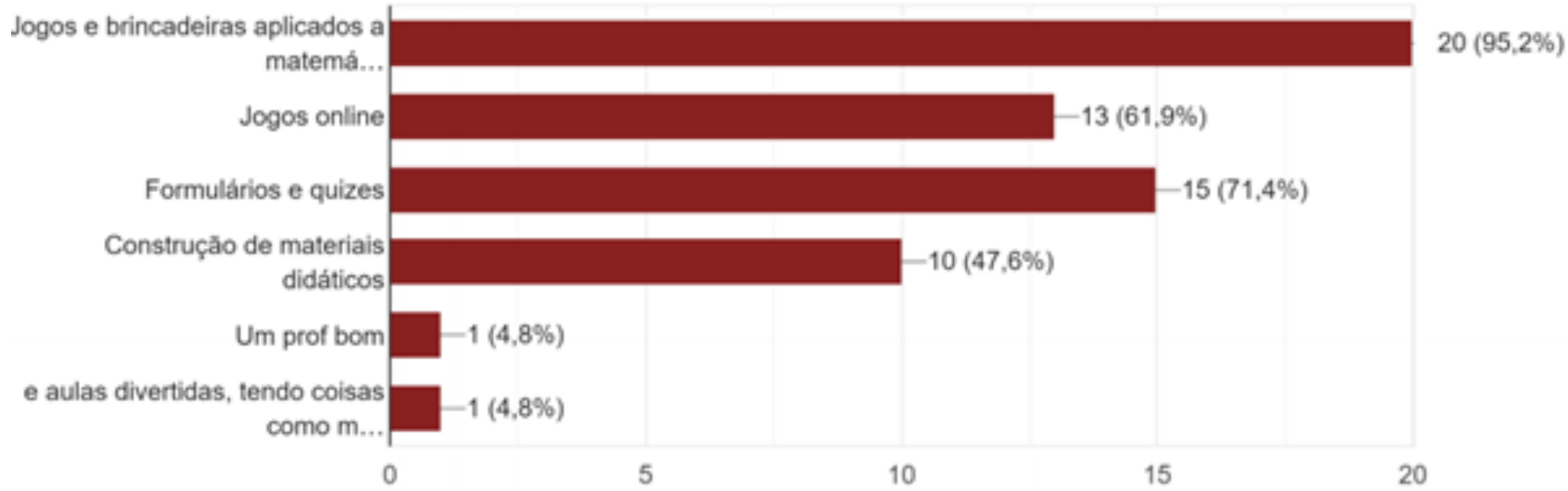

Fonte: Gráfico construído com os dados coletados no questionário.

Da análise dos dados observa-se que na opinião dos entrevistados os jogos e brincadeiras aplicados à matemática são a fonte de maior eficácia para auxílio ao aprendizado da disciplina, seguido de formulários e quizes. Importante destacar, que a metodologia foi aplicada em um período de pandemia (Pandemia de COVID19), sendo assim, as técnicas foram aplicadas de modo remoto. Desta forma, algumas técnicas julgadas por professores e matemáticos como eficientes na ludicidade da disciplina, não caíram no gosto da turma. Métodos como confecção de jogos e da régua operatória, ligação de filmes com a matemática, foram exemplos de técnicas que seriam trabalhados de forma mais eficaz no regime presencial, visto que, propiciam momentos de interação com a turma e professor em sala de aula, e no regime remoto, os discentes, precisam fazer estes trabalhos sozinhos, em sua maioria, acarretando em um trabalho mais complexo e às vezes maçantes.

Outra questão abordada no questionário está relacionada às diversas técnicas utilizadas com a turma entrevistada durante a aplicação da metodologia. Estas técnicas tinham como objetivo propiciar aos discentes um contato com a matemática de uma forma diferente da tradicional, onde a ludicidade e o novo foram pontos principais, e a peça chave era despertar na turma o gosto pela disciplina. Os resultados desta análise podem ser sintetizados conforme tabela (Tabela 01). 
Tabela 01 - Síntese do conhecimento dos entrevistados referente à análise das técnicas aplicadas de ensino da matemática.

\begin{tabular}{|c|c|c|c|}
\hline $\begin{array}{l}\text { Técnicas mais } \\
\text { apreciadas pela } \\
\text { turma }\end{array}$ & $\begin{array}{c}\text { Técnicas menos } \\
\text { apreciadas pela } \\
\text { turma }\end{array}$ & $\begin{array}{l}\text { Técnicas mais } \\
\text { relevante para } \\
\text { construção do } \\
\text { conhecimento }\end{array}$ & $\begin{array}{l}\text { Técnicas menos } \\
\text { relevante para } \\
\text { construção do } \\
\text { conhecimento }\end{array}$ \\
\hline $\begin{array}{l}\text { Registros com fotos } \\
\text { pela cidade: } \\
\text { Números inteiros } \\
\text { no cotidiano }\end{array}$ & $\begin{array}{l}\text { Produções textuais } \\
\text { de diversos temas } \\
\text { relacionando a } \\
\text { matemática }\end{array}$ & Listas de exercícios & $\begin{array}{l}\text { Produções textuais } \\
\text { de diversos temas } \\
\text { relacionando a } \\
\text { matemática }\end{array}$ \\
\hline Listas de exercícios & $\begin{array}{c}\text { Confecção de régua } \\
\text { operatória }\end{array}$ & Aulas simuladas & $\begin{array}{c}\text { Associação de filmes } \\
\text { a matemática }\end{array}$ \\
\hline $\begin{array}{l}\text { História em } \\
\text { quadrinhos: } \\
\text { Expressões } \\
\text { numéricas no } \\
\text { cotidiano }\end{array}$ & $\begin{array}{l}\text { Confecção do jogo } \\
\text { da memória da } \\
\text { divisão dos números } \\
\text { inteiros e vídeo do } \\
\text { jogo em família }\end{array}$ & $\begin{array}{c}\text { Trabalhos de } \\
\text { pesquisa }\end{array}$ & $\begin{array}{c}\text { Confecção de régua } \\
\text { operatória }\end{array}$ \\
\hline
\end{tabular}

Fonte: Tabela construída com os dados coletados na aplicação do questionário

Os últimos pontos abordados no questionário tiveram como objetivo a coleta de sugestões acerca do estímulo ao ensino da matemática por parte dos professores. Os entrevistados relataram que é muito importante que os docentes saiam de sua zona de conforto e apostem em situações como: trabalhos práticos; utilização de recursos digitais; jogos; estimular o aluno a sair de sua comodidade e ir às ruas fazer atividades, vendo desta forma, os locais onde a matemática está presente; utilizar uma linguagem mais amiga e humana, não passando temor aos alunos e motivando os mesmos; não amedrontar os discentes com o drama de provas, trabalhos e notas baixas, dentre outras ações. Os alunos apontam também, que sentem nitidamente quando o docente não gosta do que faz e que estas atitudes refletem neles.

\section{CONCLUSÃO}

0 projeto alcançou os objetivos propostos, obtendo resultados que contribuem para um panorama especial, em referência ao incentivo da matemática nos anos finais do ensino fundamental. Nesse aspecto, o trabalho torna-se ferramenta de auxílio aos docentes que queiram diversificar suas técnicas. Mesmo que a matemática seja uma disciplina complexa, se seus preceitos forem construídos de uma forma agradável e motivadora, é possível termos alunos com afeição pela mesma, facilitando desta forma a construção do aprendizado. Ao avaliar os dados obtidos na aplicação, é possível observar estudantes almejando professores que sejam mais próximos e mais acessíveis. Além disso, é possível notar, que a presença da ludicidade na vida escolar, facilita a assimilação dos conteúdos. Verificou-se que um aluno pode saber a matéria, e não necessariamente obter um "dez" em uma avaliação escrita, mas obter um resultado satisfatório através de uma apresentação oral ou ainda através da 
dramatização de um teatro, ou outra técnica. Analisar e ser sensível às diversas formas que um discente pode assimilar o conteúdo, é uma tarefa que cada professor deve desenvolver. De acordo com os relatos dos alunos, que a ludicidade, não está muito presente nas instituições educacionais, assim como a associação da matemática ao cotidiano. Ainda prevalece o formato de ensino tradicional, trazendo aulas expositivas e aplicação de instrumentos de avaliação (prova). Por fim, cabe ao educador analisar a situação de seus alunos, e proporcionar diversas maneiras de se aprender um determinado conteúdo, sempre fazendo um trabalho de análise e acompanhamento para ver se a referida técnica está dando frutos.

\section{REFERÊNCIAS}

BORIN, J. Jogos e Resolução de Problemas: Uma estratégia para as aulas de matemática. $2^{\text {a }}$ ed. São Paulo: IMESP, 1996.

BRANDT, C. F., MORETTI, M. T. (Org.). Ensinar e aprender matemática: possibilidades para a prática educativa/ Ponta Grossa : Ed. UEPG, 2016.

DULLIUS, M.M. (Org.) Brincando e aprendendo matemática. Lajeado: Ed. da Univates, 2015. Disponível em https://www.univates.br/editora-univates/media/publicacoes/143/pdf_143.pdf.

MENDES, L.M.C. SILVA, M.V, A Importância do Lúdico no Ensino da Matemática, prática de ensino da Escola Municipal Professor Luiz Carlos Alves da Cruz, 18 de setembro de 2011.

LYONS, I.M. \& BEILOCK, S.L. Quando a matemática dói: a ansiedade pela matemática prediz a ativação da rede de dor na expectativa de fazer matemática. 2012. Disponível em: https://journals.plos.org/plosone/article?id=10.1371/journal.pone.0048076.

MORAES, Paula Louredo. "Discalculia, sintomas, causas e tratamento"; Brasil Escola. Disponível em: https://brasilescola.uol.com.br/doencas/discalculia.htm.

PARÂMETROS CURRICULARES NACIONAIS (PCNS). Introdução. Ensino. Fundamental. Brasília: MEC/SEF,1998.

. Parâmetros Curriculares Nacionais (PCNs). Matemática. Ensino. Fundamental. Terceiro e quarto ciclos. Brasília: MEC/SEF, 1998.

PARRA, C. SAIZ, I. Didática da Matemática: Reflexões Psicopedagógicas. Porto Alegre, Artmed (Artes Médicas). 1996.

PIAGET, Jean. Sobre a pedagogia. São Paulo: Casa do Psicólogo, 1998.

SILVA, E. C. da (Org.). Ensino aprendizagem de matemática [recurso eletrônico]. Ponta Grossa (PR): Atena Editora, 2019.

VITTI, Catarina Maria. Matemática com prazer. São Paulo: UNIMEP, 1996. Disponível em: <https://www.vittude.com/blog/discalculia-dificuldade-matematica. Acesso em 21.set.2019>. 


\section{ANEXOS}

ANEXO A - Modelo do questionário para os discentes envolvidos respondido via Google Forms

1. Você já detestou a matemática?

2. Que motivos você cita para não gostar da matemática?

3. 0 medo imposto por alguns professores nas provas de matemática contribuem para que os estudantes desenvolvam o medo e desinteresse pela mesma?

4. Tens conhecimento que em alguns casos a dificuldade com disciplinas da área das ciências exatas, pode estar associada a um transtorno chamado de discalculia?

5. A matemática é uma disciplina temida por muitos. Você acha que se os professores forem mais próximos dos alunos, abrindo espaço para diálogo, amizade (Professor / aluno) e criar um certo vínculo com a turma, facilita na construção do aprendizado?

6. Assinale as atividades que ao seu ver, são de maior eficácia no auxílio ao ensino da matemática.

$\square$ Jogos e brincadeiras aplicados à matemática (Jogos manuseáveis)

Jogos online

Formulários e quizes

Construção de materiais didáticos

Outros

7. Assinale a técnica que mais lhe agradou

Aula síncrona

Aulas Simuladas

Confecção da régua operatória

Confecção do jogo da memória da divisão dos números inteiros e vídeo do jogo em família

Filmes e a matemática

Fotos e entrevista: Potência no cotidiano

História em quadrinhos: Expressões numéricas no cotidiano

Listas de exercícios

Produções textuais de diversos temas relacionando a matemática e ao conteúdo em questão

Provas (Verificação do aprendizado)

Registro com fotos pela cidade

Números inteiros no cotidiano

Trabalhos de pesquisa

8. Assinale a técnica que menos lhe agradou

$\square$ Aula síncrona

Aulas Simuladas

Confecção da régua operatória

Confecção do jogo da memória da divisão dos números inteiros e vídeo do jogo em família

Filmes e a matemática

Fotos e entrevista: Potência no cotidiano

História em quadrinhos: Expressões numéricas no cotidiano

Listas de exercícios

Produções textuais de diversos temas relacionando a matemática e ao conteúdo em questão

Provas (Verificação do aprendizado)

Registro com fotos pela cidade

Números inteiros no cotidiano

Trabalhos de pesquisa

9. Qual das atividades realizadas foi a mais relevante na construção de seu aprendizado?

Aula expositiva síncrona

Aulas Simuladas

Confecção da régua operatória

Confecção do jogo da memória da divisão dos números inteiros e vídeo do jogo em família

Filmes e a matemática

Fotos e entrevista: Potência no cotidiano

História em quadrinhos: Expressões numéricas no cotidiano

Listas de exercícios 
Produções textuais de diversos temas relacionando a matemática e ao conteúdo em questão

Provas (Verificação do aprendizado)

Registro com fotos pela cidade

Números inteiros no cotidiano

Trabalhos de pesquisa

10. Qual das atividades realizadas foi a menos relevante na construção de seu aprendizado?

Aula síncrona

Aulas Simuladas

Confecção da régua operatória

Confecção do jogo da memória da divisão dos números inteiros e vídeo do jogo em família

Filmes e a matemática

Fotos e entrevista: Potência no cotidiano

História em quadrinhos: Expressões numéricas no cotidiano

Listas de exercícios

Produções textuais de diversos temas relacionando a matemática e ao conteúdo em questão

Provas (Verificação do aprendizado)

Registro com fotos pela cidade

Números inteiros no cotidiano

Trabalhos de pesquisa

11. Para o ensino da matemática em tempos de pandemia, qual das técnicas abaixo é mais propicia para se aprender a disciplina em questão?

Aula síncrona (Google Meet)

Aula Assíncrona (Através de atividades determinadas)

Vídeo aulas

12. Em que situações em seu cotidiano ou em ocasiões passadas, esteve em contato com situações de aversão ao estudo dos números?

13. De que forma você acredita que os profissionais da área da matemática devem estimular o ensino da mesma? 